\title{
O EU E O OUTRO NO ENSINO MÉDIO INDÍGENA: ALTO RIO NEGRO (AM)
}

\author{
Dulce Maria Pompêo de Camargo \\ Judite GonÇALVES DE AlbUQUerQue**
}

\begin{abstract}
O nosso ativíssimo prelado D. Pedro Massa insistiu para que fossem registrados, com a máxima fidelidade, os usos e costumes desses índios, porque mais tarde seria um trabalho mais difícil de realizar, pelo fato de que a civilização e a moral avançam rapidamente naquela região, sendo educados e instruídos gratuitamente os pequenos índios mantidos nas escolas da Missão Salesiana, a saber, 400 crianças internadas nos três centros escolares de Taracuá, Iauaretê e Pari-Cachoeira.
\end{abstract}

(Antonio Giaconne, 1949, p. 9)

RESUMO: As reflexões apresentadas estão calcadas nas experiências vivenciadas por nós em projetos de formação de professores índios e nos dados coletados em uma pesquisa de campo, no alto Rio Negro, no que se refere: a) aos usos lingüísticos em sala de aula onde estudam alunos de dez a vinte etnias e línguas diferentes; b) ao projeto político-pedagógico das escolas; c) às dificuldades dos alunos em função de sua origem indígena. Para alcançar o objetivo proposto, apresentamos uma análise do 'sistema preventivo' de educação para jovens, proposto por D. Bosco, em meados do século XIX, e seguido, ainda hoje, pelos missionários salesianos que atuam na região. Tais reflexões podem subsidiar, de um lado, a apresentação de pro-

* Doutora em Educação pela Universidade Estadual de Campinas (UnICAMP) e professora do Programa de Pós-Graduação em Educação da Pontifícia Universidade Católica de Campinas (PUC-CAMPINAS). E-mail: dpompeo@mpc.com.br

** Mestre em Educação pela Universidade Federal de Mato Grosso (UFmT), doutoranda em Lingüística pela UNICAMP e professora aposentada da Universidade do Estado de Mato Grosso (UNEMAT).E-mail: juditeg@terra.com.br

Disponível em <http://www.cedes.unicamp.br> 
O eu e o Outro no ensino médio indígena: Alto Rio Negro (АМ)

postas que contribuam para a formulação de políticas de educação para o ensino médio indígena em todo o país e, de outro, contribuir para a construção de sistemas autônomos de educação, superando políticas integracionistas. Nossos principais interlocutores são autores ligados à perspectiva pós-colonial: Bhabha (2005), Hall (In: Sovik, 2003), Souza Santos (2000) e Shiva (2003).

Palavras-chave: Práticas pedagógicas. Formação de professores índios. Pós-colonialismo.

THE SELF AND THE OTHER IN INDIGENOUS SECONDARY EDUCATION: ALTO RIO NEGRO (AM)

ABSTRACT: The reflections here presented are based on our experiences in projects to train Indian teachers and on the data collected in a field research, in the alto Rio Negro, with regard to: a) the linguistic uses in classroom with students from ten to twenty different ethnic groups and languages; b) the political-pedagogical project of the schools; c) the difficulties faced by students because of their indigenous origin. To meet the objective proposed, we present an analysis of the 'prevention system' of youth education, proposed by D. Bosco in the mid-XIXth century, and still used by the Salesian missionaries who live in the region. Such reflections can support the presentation of proposals that contribute, on the one hand, to formulate educational policies for indigenous secondary education in Brazil and, on the other, to build autonomous education systems, overcoming integrationist policies. Our main interlocutors are authors linked to the post-colonial perspective: Bhabha (1998), Hall (In: Sovik, 2003), Souza Santos (2000) and Shiva (2003).

Key words: Pedagogical practices. Indian teacher formation. Post-colonialism.

A realização de uma pesquisa de campo $^{1}$ para conhecer as demandas e as condiçôes de escolarização em nível médio dos povos indígenas, na região do alto e médio Rio Negro (AM), faz parte de um trabalho mais amplo, desenvolvido pelo MEC/SEMTEC, que buscou ter, assim, condições de apresentar propostas que possam contribuir para a formulação de políticas de educação para o ensino médio indígena em todo o país, incluindo a formação de professores indígenas. Tal diagnóstico está inserido no Programa Diversidade na Universidade e visa contribuir para a construção de sistemas autôno- 
mos de educação, superando políticas integracionistas que, ao longo de séculos de colonização, tentaram fazer desaparecer os índios como naçóes e como identidades individuais, na medida em que a educação lhes roubava a língua, os costumes, a religião, a cultura. Trata-se de um esforço coletivo de superação da hegemonia do urbano, possibilitando a universalização da educação básica.

A pesquisa de campo permitiu coletar, de maneira sistemática, os dados referentes à demanda por ensino médio no alto e médio Rio $\mathrm{Ne}$ gro, dados sobre a oferta desse nível de ensino, analisando as condiçōes da oferta e focalizando, sobretudo, os graves problemas gerados para as comunidades a partir da nuclearização da educação escolar tanto do ensino médio, como também do ensino fundamental ( $5^{\mathrm{a}}$ a $8^{\mathrm{a}}$ séries). Tais dados permitiram, ainda, analisar as condições de funcionamento das escolas de ensino médio, levantar dados sobre a formação dos professores e as condiçôes de vida dos alunos que deixam as próprias comunidades para estudar nos Centros Missionários Salesianos ou na cidade de São Gabriel da Cachoeira.

Esta coleta de dados e a posterior análise provocaram um abalo quanto à crença anterior de que as escolas da região são 'indígenas', ${ }^{2} \mathrm{o}$ que nos instigou a pensar com maior profundidade sobre o assunto; o objetivo deste artigo é descrever e analisar as condições da educação escolar dos alunos indígenas, dentro e fora das terras indígenas: a) os problemas de usos lingüísticos em sala de aula, onde dividem o mesmo espaço alunos de dez a vinte etnias e línguas diferentes; b) o projeto político-pedagógico das escolas, contextualizando conteúdos e processos de ensino-aprendizagem; c) as dificuldades vivenciadas pelos alunos em função de sua origem indígena.

Para alcançar o objetivo proposto, começamos apresentando uma análise do 'sistema preventivo' de educação para jovens, proposto por D. Bosco para educar meninos internos, na cidade de Turim, Itália, em meados do século XIX, e seguido, ainda hoje, pelos missionários salesianos que atuam nesta região, conforme se pode verificar no Regimento Escolar da Diocese de São Gabriel, o mesmo para todas as escolas.

Para entender este sistema, tomamos como referência a dissertação de mestrado Homem: objetivação de uma sujeição (Gomes, 1991), na qual o autor mostra como funciona o 'sistema preventivo' de educação de D. Bosco e como se situa teoricamente o sistema e a "insuspeita 
O eu e o Outro no ensino médio indígena: Alto Rio Negro (AM)

aliança entre o poder pastoral (sistema preventivo) e o poder disciplinar (o poder das sociedades modernas) para educar o cidadão honesto, isto é, estudioso, dócil e bom cristão" (p. 6). Tal referencial fundamenta nossa análise no que diz respeito aos dados da oferta do ensino médio na região, tomando por base quatro questôes que foram colocadas pelos participantes do I Seminário sobre Ensino Médio em São Gabriel da Cachoeira, realizado em março de 2004, e que se constituiu como o ponto de partida para o trabalho de campo realizado.

O 'sistema preventivo' de educação salesiana para jovens

O sistema de educação das escolas salesianas que atuam no Rio Negro é o Sistema Pedagógico de D. Bosco baseado no trinômio RazãoReligião-Amabilidade, ${ }^{3}$ bastante conhecido como 'sistema preventivo'. $\mathrm{O}$ fato de a educação escolar na região ter estado, desde 1914, e estar ain$\mathrm{da}$, em grande parte, sob a responsabilidade dos missionários salesianos, ${ }^{4}$ exigiu de nós a análise do projeto político-pedagógico das escolas, para que obtivéssemos informações de como funciona este sistema preventivo de educação da juventude. Uma proposta que se propagou muito rapidamente pelo mundo ocidental (e ocidentalizado), exatamente porque coincidia com os cânones da sociedade disciplinar do início do século XIX, descrita por Foucault (Gomes, 1991).

$\mathrm{O}$ autor nos mostra como o poder pastoral ${ }^{5}$ desenvolvido na e pela Igreja começou a perder o seu vigor após o século XVIII, quando, a partir dessa matriz, o Estado moderno propôs uma nova forma de poder pastoral. Em ampla pesquisa nos escritos do próprio J. Bosco, por um lado, e na obra de Foucault, por outro, o autor se dedicou a aprofundar-se sobre os sentidos do 'sistema preventivo' de educação salesiana. E justifica o seu interesse: "pela simples razão de haver sido o estofo de gestação do atual poder disciplinar, o poder pastoral já mereceria cuidadosa atenção. Além disso, se essa matriz de poder perdeu seu vigor, ainda não desapareceu" (1991, p. 104. Grifos nossos).

Concordando com Gomes e baseando-nos em sua pesquisa sobre o 'sistema preventivo', um corpo de idéias que reúne práticas que se tornaram tradição, normas pedagógicas e regulamentos aplicados à gestão das escolas salesianas, desde a segunda metade do século XIX, tentamos mostrar como essa forma de educação introduzida nas comunidades indígenas 
do alto e médio Rio Negro continua produzindo seus efeitos colonizadores: "(...) o pós-colonial marca a passagem de uma configuração ou conjuntura histórica de poder para outra. Problemas de dependência, subdesenvolvimento e marginalização, típicos do alto período colonial, persistem no pós-colonial” (Hall, in: Sovik, 2003, p. 56).

Conforme Gomes (1991, p. 102), "ou a obra de J. Bosco se ajustava aos cânones da sociedade disciplinar ou desaparecia, sufocada pelo ar rarefeito de aceitação à tentativa de ser diferente". Este sistema de educação não desapareceu, o que nos leva a concluir que ele se ajustou às malhas do contexto da rede do poder disciplinar, que perpassa a sociedade ocidental desde o início do século XIX.

O poder pastoral é uma forma complexa e muito particular de poder que combina procedimentos que dizem respeito ao conjunto da população e outros que atingem os indivíduos de maneira a sujeitá-los e a fazê-los produzir uma verdade sobre si mesmo. O objetivo final é "assegurar a salvação dos indivíduos no outro mundo" (Gomes, 1991, p. 105). Derivado do poder pastoral, o poder político cuida da salvação do indivíduo aqui mesmo, neste mundo. A obra de J. Bosco propõe, em resumo, "formar bons cristãos e bons cidadãos", daí a freqüente e eficiente aliança com o poder político, que sempre caracterizou o desenvolvimento dos trabalhos dos religiosos salesianos onde quer que se instalem; no Rio Negro não foi diferente: vieram dispostos a "incorporar aquelas tribos à civilização brasileira e cristã" (D. Massa, 1965, p. 87, apud Silva, 1994). E como, no entendimento de J. Bosco, "o bom cristão é aquele que tem os pés na terra e a cabeça no céu" (Gomes, 1991, p. 106), o 'sistema preventivo' articula uma série de práticas e discursos que ajudam os adolescentes e jovens, sempre tão dispersos e preocupados apenas com o momento presente (aqui e agora), "a levantar os olhos para o alto" (idem, ibid., p. 106), fazendo-os lembrar que estão neste mundo de passagem e que sua morada permanente é o céu.

Nos internatos salesianos para os povos indígenas, incluindo os do Rio Negro, além dos gestos de contínuo rememorar das coisas do céu, o 'sistema preventivo' tem também a preocupação de fazer o interno viver em permanente "estado de conversão": para chegar a esse estado, havia o "exercício da boa-morte", acontecimento mensal que alterava a rotina de todo um dia para que o aluno assistisse a conferências, 
O eu e o Outro no ensino médio indígena: Alto Rio Negro (AM)

nas quais se lembrava aos ouvintes o destino eterno de cada um e que a sorte desse destino se joga nesta vida.

E uma vez ao ano, geralmente na semana santa, havia os "exercícios espirituais": cinco dias de silêncio absoluto, com orações e reflexões. Tanto no exercício da boa-morte como nos exercícios espirituais cada aluno devia traçar seu programa de vida e submetê-lo à apreciação do diretor espiritual.

Esse poder pastoral de salvação é relacionado diretamente à capacidade de sofrimento do educador, que deve estar pronto para dar a vida pela salvação do rebanho. Por isso, somente o cristão pode aplicar com êxito o 'sistema preventivo'. O etnólogo padre Brüzzi Alves da Silva (1975) confirma essa idéia, em seu livro $A$ civilização indígena do Uaupés, ao comentar que a expulsão dos jesuítas da Província do Amazonas pelo Marquês de Pombal tinha feito fracassar os nobres planos de catequese e educação dos índios.

O padre Brüzzi continua o seu relato, dando conta das boas obras que os poucos missionários conseguiam fazer em alternados periodos de assistência atentos aos incolas do Rio Negro, até a chegada definitiva dos salesianos:

Em 1914, a Missão do Rio Negro e Uaupés foi confiada pela Santa Sé à Congregação Salesiana de S. João Bosco e inicia-se nova e mais promissora fase para aquelas tribos. (...) Os índios são atraídos para as margens desses rios e aldeados em pequenos povoados. Para a mais perfeita assimilação civilizadora, conforme os princípios cristãos (...). (Silva, 1975, p. 20)

Ficam evidentes, no texto citado, os objetivos da Missão, a mesma para qualquer parte do mundo, inspirada no fundador dos oratórios que, em todos os lugares, foram se transformando em internatos, onde a vigilância contínua garante a transformação dos estudantes em criaturas dóceis e úteis, moldando as individualidades segundo um padrão desejável. Pois essa é outra faceta do poder pastoral, o enquadramento do comportamento individual para adequá-lo a um "modelo divino", inalcançável por definição, ficando o homem sempre cativo de uma 'dívida infinita' para com Deus.

É o filósofo contemporâneo Gilles Deleuze (Abecedário de Deleuze, 1996) ${ }^{6}$ que mostra como o poder separa as pessoas que estão a ele submissas daquilo que elas podem fazer, restando a tristeza da inca- 
pacidade, do jamais alcançar o que se pretende. Essa é uma invenção do cristianismo. O padre inventou uma "dívida infinita para com Deus". Nas sociedades primitivas, havia "dívidas finitas". Para saldar as dívidas, havia as trocas. A dívida precedia a troca. Aqui, não. A pessoa nasce, permanece, para sempre, devedora para com Deus e para com aquelas "bondosas pessoas" que se dedicam incansavelmente no trabalho da educação. Essa "dívida infinita" é uma invenção histórica do cristianismo (não de Cristo, certamente!). Outra forma de cativeiro. Assim, o objetivo de se tornar "bom cristão" e "honesto cidadão" é tão amplo e difuso que dentro dele cabem todas as exigências dos "superiores" e somente eles têm o poder de decidir e avaliar toda e qualquer atividade do aluno; não há uma medida exata para se atingir, com o "estudo, a piedade, a alegria", mas somente eles poderão dizer "se a alegria é sadia, se o sucesso do estudante não é manifestação de soberba, se a piedade não é fingida (...)" (Gomes, 1991, p. 113).

Para se chegar ao coração mesmo do 'sistema preventivo', os internatos têm toda uma organização interna de vigilância constante que, aparentemente, não agride, como o sistema repressivo, que vigia para identificar as falhas e puni-las; aqui não, a vigilância é uma espécie de assistência que coloca os jovens na "impossibilidade de cometer falhas"; nas instituições salesianas, cada aluno, ao chegar, é discretamente designado para uma "divisão": maiores, menores e médios. Cada divisão tem seu lugar marcado, sempre o mesmo, seu dormitório, seu espaço no refeitório, na sala de aula, na sala de estudo, na igreja, no pátio. E cada aluno, dentro da sua divisão, ocupa sempre a mesma posição, a mesma carteira na sala e o mesmo lugar na mesa do refeitório. Os de uma divisão são proibidos de conversar com os outros da outra divisão. Não se pode afastar da divisão, sem avisar ao assistente. Durante 24 horas por dia o aluno está sendo acompanhado, observado ("assistido") pelos assistentes e vice-assistentes.

E, por fim, o "Regulamento", um conjunto de normas - geralmente muitas! - que cria o modo uniforme segundo o qual as coisas devem ser feitas. A observância das regras produz santos, é o que se pode deduzir do tom das narrativas da vida dos santos que são lidas no internato. Jovens que são capazes de deixar uma palavra escrita na metade, porque tocou o sino e é preciso obedecer. Os regulamentos, longos e minuciosos, descrevem as funções de cada encargo, a maioria das quais exercida pelos próprios alunos. "Esta técnica realiza uma dupla 
O eu e o Outro no ensino médio indígena: Alto Rio Negro (AM)

imposição: impõe aos que melhor se sujeitarem, o prêmio de impor, aos colegas, os regulamentos da instituição" (idem, ibid., p. 117).

$O$ poder pastoral se exerce plenamente na medida em que os superiores puderem conhecer o que se passa na cabeça das pessoas, explorar suas almas, forçando-as a revelar seus segredos mais íntimos. $\mathrm{O}$ mestre espiritual interroga o aluno, obrigando-o "a falar das suas próprias motivações, do vacilar da vontade, do lampejo do pensamento, dos deleites dos sentidos" (idem, ibid., p. 118) e ensina-os a fazer o "exame de consciência": "olhar para o que se é e não deveria ser, e olhar para o que deveria ser, mas ainda não se é", "a verdade-de-si", não de qualquer verdade, mas de uma verdade de salvação, a mesma para todos, inibindo a possibilidade de cada um fazer uma "experiência de si" diferente.

O poder pastoral interfere claramente nos processos individuais de subjetivação e o sujeito pedagógico resulta, então, da articulação, por um lado, entre os discursos que o nomeiam e, por outro lado, das práticas institucionalizadas que o capturam, para torná-los "dóceis e úteis".

Tomamos, para exemplificar a aplicação do 'sistema preventivo' no Rio Negro, um texto de 1949, do padre Antônio Giaconne, que relata a "História de um indiozinho da Missão de Taracuá", no rio Uaupés (AM).

Trata-se de episódio histórico em todas as suas particularidades, servindo para revelar a grande dificuldade de educar e levar o indio à civilização. Nós, salesianos, cumprindo a ordem do santo fundador, S. João Bosco, procuramos atrair a nós a juventude, colocando-a nos internatos, com escolas, oficinas e trabalhos agrícolas. Verificamos, pela experiência, que esse é, ainda, o melhor sistema para conduzir também os adultos à civilização e à luz do evangelho. (Giaconne, 1949, p. 3. Grifos nossos)

Conta o padre que, em 1927, apareceu na Missão um indiozinho de seus sete anos, acompanhando uma família de dessanos e que "se tornou logo conhecido por sua índole fogosa e esperteza em tirar tudo o que pudesse servir para os seus dentes". O relato traz, com detalhes, os passos pelos quais o "indiozinho, o pequeno vagabundo" (assim o nomeia o Padre) foi passando no doloroso processo de "civilizar-se: Vivia como um animal, (...) não tendo cama para dormir (...) passava as noites no meio dos cáes; arrancava a macaxeira e a roia como os ratos do mato; girava pela missão como um cachorrinho esfaimado; alimen- 
tava-se na missão e dormia fora, passando o dia na vagabundagem"; quando um civilizado, de passagem pela Missão, quis levá-lo como empregado,

O missionário interveiu [sic] no contrato e não permitiu que fosse levado, porque sabia que o pobrezinho perderia para sempre a liberdade. Depois de algum tempo, o pequeno órfão (...) entrou na missão como interno. Não é fácil descrever o que se passou naquela alma selvagem, até chegar a uma completa transformação. O sistema de D. Bosco, apoiado todo na razão, na religião e no carinho, aplicado entre os civilizados, deu, também aqui, ótimos resultados. (...) Depois de dois anos de luta, passou a ser um menino dócil e obediente, e aprendeu não só a ler e a escrever, mas também o ofício de carpinteiro, tornando-se elemento útil à pátria e motivo de satisfação para os seus educadores. (1949, p. 83-85. Grifos nossos)

Transcrevemos esses trechos da "história do indiozinho" com o objetivo de evidenciar como funcionam os dispositivos pedagógicos da educação escolar entre os índios, baseada no 'sistema preventivo', e como se articulam, por um lado, os discursos que "nomeiam o índio" e, por outro lado, "as práticas institucionalizadas que o capturam" para torná-lo "dócil e útil (...)".

São os dispositivos pedagógicos funcionando. Um sistema que toca sem manchar, que amolda sem ferir. É a vigilância contínua colocando os internos na impossibilidade de cometer faltas, mas também esterilizando toda possibilidade de fazer uma experiência de si diferente (Gomes, 1991, p. 142).

Ensino médio dentro e fora de terra indígena: propostas locais de mudança

\footnotetext{
Em geral, o índio gosta de aprender e civilizar-se para "virar branco", como dizem, pois serão convencidos de que, uma vez educados, são capazes de fazer as mesmas coisas que fazem os civilizados. (Giaconne, 1949, p. 70)
}

Em nosso entender, o Ensino Médio "Indígena" ainda não existe em funcionamento no Alto Rio Negro. O tipo de ensino oferecido hoje pelos missionários, em Iauaretê e São Gabriel, é o mesmo que é dado em qualquer estado e município do país, não trata das questões indíge- 
O eu e o Outro no ensino médio indígena: Alto Rio Negro (AM)

nas especificamente, não prioriza a cultura indígena, não organiza o currículo em torno dos projetos das sociedades indígenas. "O trabalho fronteiriço da cultura exige um encontro com o 'novo' que não seja parte do continuum de passado e presente. Ele cria uma idéia do novo como ato insurgente de tradução cultural" (Bhabha, 2005, p. 27).

As idéias do autor, fundamentadas no pós-colonial, nos ajudam a perceber porque isso ocorre: o ensino médio, desde a sua implantação, em São Gabriel (1976) e Iauaretê (1988), não tem sido pensado pelos indios, está sendo feito para os indios. Isso já traz dificuldade básica porque qualquer tentativa de fora para dentro da sociedade indígena é artificial, é de fora! E imprime os objetivos da outra sociedade. E uma educação escolar pensada por outra sociedade tende a enfraquecer a raiz de um povo, o seu lado espiritual, a sua língua, a sua cultura, o seu jeito de pensar, o seu jeito de ver o mundo... Essas coisas que as pessoas recebem do pai e da mãe, através da língua, na mitologia, na história, naquilo que cada povo foi construindo...

Nesse momento "pós-colonial", os movimentos transversais, transnacionais e transculturais, inscritos desde sempre na história da "colonização", mas cuidadosamente obliterados por formas mais binárias de narrativização, têm surgido de distintas formas para perturbar as relações estabelecidas de dominação e resistência inscritas em outras narrativas e formas de vida. Eles reposicionam e deslocam a "diferença" sem que, no sentido hegeliano, se atinja sua "superação". (Hall, in: Sovik, 2003, p. 114)

Em São Gabriel da Cachoeira, há muito que as comunidades gritam por uma educação escolar própria, ainda que embrionariamente e ainda que contando com uma ação clara do poder público. Esse anseio teve uma expressão forte no seminário "Os povos indígenas no alto e médio Rio Negro e a educação escolar: construindo um ensino médio específico", promovido conjuntamente pelo MEC/SEMTEC e pelo Conselho dos Professores Indígenas do Alto Rio Negro (COPIARN), no período de 8 a 10 de março de 2004, com o objetivo de avaliar a situação do ensino médio que está sendo oferecido na regiāo, discutir e formular diretrizes e políticas para implantação do ensino médio específico nas escolas indígenas do alto e médio Rio Negro.?

Em suma, o I Seminário veio atender aos anseios dos diversos povos indígenas do Rio Negro que, representados por lideranças, associações, escolas e entidades exigiram 
uma postura mais responsável (democrática, solidária e de respeito) refletida em ações concretas por parte do poder público municipal (SEMEC), estadual (SEDUC) e federal (MEC/SEMTEC) na implantação do ensino médio especifico e diferenciado nas escolas indígenas assegurados pela Constituição Federal, pela Lei de Diretrizes e Bases da Educação Nacional (Lei 9394/96) pela Resolução no 03/1999 do Conselho Nacional de Educação, pela Resolução no 11 do Conselho Estadual de Educação do Amazonas e pela Lei Municipal no 135/2001, que reorganiza o Sistema Municipal de Educação Indígena de São Gabriel da Cachoeira. (I Seminário, 2004, p. 6)

Este I Seminário teve uma importância muito grande na região, porque foi um momento em que os professores participantes se posicionaram e pediram insistentemente que o regimento escolar da Diocese de São Gabriel da Cachoeira, em funcionamento, fosse substituído por projetos político-pedagógicos das escolas e que pudessem ser amplamente discutidos entre professores, pais, alunos, entidades indígenas e a comunidade em geral, respeitando a diferença cultural dos povos indígenas, suas línguas, seu patrimônio histórico; que cada escola, trabalhando de forma crítica, por meio da pesquisa, passasse a utilizar os conhecimentos tradicionais das etnias, no diálogo com as outras culturas.

A partir do I Seminário, as escolas de Pari Cachoeira, Taracuá e Assunção do Içana começaram a realizar suas pesquisas com o objetivo de fazer uma proposta de descentralização e de implantação de um ensino médio próprio. Reivindicam um calendário diferenciado, com uma previsão de duração dos cursos com o tempo necessário para a formação do aluno e uma gestão indígena, substituindo as irmãs diretoras. É uma dura batalha, uma vez que a diocese não se mostra favorável à retirada das irmãs da direção das escolas. "Uma vez que as relações que caracterizaram o 'colonial' não mais ocupam o mesmo lugar ou a mesma posição relativa, podemos não somente nos opor a elas mas também criticar, desconstruir e tentar 'ir além' delas" (Hall, in: Sovik, 2003, p. 119).

Nos relatos dos participantes do I Seminário há claramente uma ansiedade por mudanças significativas. As propostas aparecem quase sempre no sentido, por um lado, de mudar a gestão das escolas, passando essa responsabilidade para quem tem as melhores condições de responder por ela, ou seja, os próprios índios; de cada escola ter seu 
O eu e o Outro no ensino médio indígena: Alto Rio Negro (AM)

próprio projeto pedagógico, pensado, elaborado e executado pelos próprios índios, de forma a valorizar os saberes tradicionais dos povos, as suas línguas (todas!) e cultura. Por outro lado, ao mesmo tempo em que as falas são lúcidas e decididas, na prática, há uma espécie de paralisia, um medo de assumir, que os imobiliza. Por que isto acontece? É isso que nos perguntamos, uma vez que a reivindicação por ensino médio indígena tem sido decisiva em vários lugares da região: "Já esperamos demais! Se não for aprovado, vamos começar do mesmo jeito!" "Queremos assumir nossas escolas! Temos pessoas com capacidade para isso"!

O que significa este "posterior" e este "ir além"? (...) "Posterior" significa o momento que sucede o outro (o colonial), no qual predomina a relação colonial. Não significa (...) que o que chamamos de "efeitos secundários" do domínio colonial foram suspensos (...). Contudo, reafirma-se aqui o fato de que configuraçōes "emergentes", porém relacionadas, de poder-saber começam a exercer seus efeitos específicos. (Idem, ibid., p. 119)

Nesses lugares, os professores e outros participantes realizaram assembléias com as comunidades, para comunicar os resultados do I Seminário, tomar as decisões locais e fazer os encaminhamentos necessários para a implantação já decidida e apoiada pelas autoridades presentes. Para nossa surpresa e, quem sabe, desencanto, em dois dos três lugares, as assembléias haviam aprovado que a gestão das escolas deveria ser feita pelos índios, mas somente dentro de um ou dois anos. Motivo: "Não temos experiência... Não estamos preparados". A isso é que estamos chamando de medo que paralisa, apesar das "configurações emergentes" de que nos fala o autor. A educação para a docilidade, para a obediência e submissão continua produzindo efeitos.

Com a "colonização" e, conseqüentemente, com o "pós-colonial", nos situamos irrevogavelmente dentro de um campo de forças de poder-saber. É justamente a distinção falsa e impeditiva entre colonização enquanto sistema de governo, poder e exploração e colonização enquanto sistema de conhecimento e representação que está sendo recusada. (Hall, in: Sovik, 2003, p. 119)

Por isso, qualquer esforço de mudança precisa ser acompanhado do entendimento profundo do que causou/causa esse medo. A educação no 'sistema preventivo', como aponta Gomes (1991), chama para a 
obediência e para a submissão, não para a criação, para a iniciativa. Os dispositivos pedagógicos do 'sistema preventivo' atuam sobre os processos de subjetivação: conduzem a uma "experiência de si" controlada, a uma verdade, sempre a mesma para todos; "os internatos indígenas foram um mal necessário", afirmou o Bispo no I Seminário. Tudo feito com muita bondade e com muita dedicação por parte dos missionários. O que não está posto é que existe um perigo maior do que não ter educação escolar: é o perigo de a educação escolar obstruir a vida enquanto potência criadora, por meio dessa prática de subjetivação dominante: aceitar ser o que os outros acham que é bom para si. Isso em todos os aspectos, inclusive o religioso.

As diferenças sociais não são simplesmente dadas à experiência através de uma tradição cultural já autenticada; elas são os signos da emergência da comunidade concebida como projeto - ao mesmo tempo uma visão e uma construção - que leva alguém para "além" de si para poder retornar, com um espírito de revisão e reconstrução, às condições políticas do presente. (Bhabha, 2005, p. 21-22)

O autor chama a atenção para o fato de que as culturas colonizadas podem ser contingentes à modernidade, resistentes à opressão assimilacionista; porém, elas também são resultado do hibridismo cultural de suas condições fronteiriças para "traduzir" e, portanto, reinscrever, tanto o imaginário social da metrópole como da modernidade. Assim, ele pode criar uma idéia do novo como ato insurgente de "tradução cultural" (idem, ibid., p. 26). Para Bhabha, no espaço da tradução a construção é sempre nova. É um sinal de que a história está acontecendo porque torna possível a negociação de instâncias contraditórias e antagônicas, que abrem lugares e objetivos híbridos de luta (p. 51).

Frente ao exposto, acreditamos que o que precisa mudar é o conceito de educação: educar para quê? Essa resposta é que tem que nascer dentro das comunidades; essa resposta não está em nenhum "livro do mestre", o que significa que a educação indígena diferenciada não existe como modelo: cada comunidade terá que inventar essa educação nova, voltada para os interesses dos povos e das pessoas; essa educação pode ajudar cada indivíduo a fazer a "experiência de si”, na comunhão com seu povo, nas relações que julgar boas para si. Mas que ele e seu povo julgarem serem boas. 
O eu e o Outro no ensino médio indígena: Alto Rio Negro (AM)

Por isso, mudança em educação não significa: cadastrar a escola como "indígena"; aumentar algumas disciplinas na parte diversificada da grade curricular da SEDUC, quase sempre "Língua Indígena", "Arte Indígena", "Agricultura Indígena”... Certamente, isso tem representado um esforço, mas em termos de mudança real tem também se revelado como um esforço inútil, porque o difícil não é fazer essas trocas ou acréscimos, o difícil é romper com as formas de ensino, com os métodos e conteúdos fixados historicamente. Difícil é fugir das manobras do conhecimento teórico dominante, que pode usar a política cultural da diferença para excluir o Outro, fazendo-o permanecer como o "dócil corpo de diferença" (Bhabha, 2005, p. 59). Difícil é encarar as possibilidades de mexer na estrutura mesma da educação, incluindo aí os objetivos, os calendários, as formas de organização das turmas e de progressão, as formas de avaliação e de registro. Difícil é produzir o material de apoio necessário para alcançar os objetivos previstos.

Não adianta remendar (o remendo novo em pano velho aumenta ainda mais o furo), porque essa educação foi estruturada sobre bases conceituais, das quais, hoje, a comunidade indígena discorda. Tanto discorda que aproveita um momento importante do I Seminário e clama: "queremos construir nossa Escola Indígena"!

As transmutações e traduções de tradições nativas, em sua oposição à autoridade colonial, demonstram como o desejo do significante e a indeterminação da intertextualidade podem estar profundamente empenhados na luta pós-colonial contra as relações dominantes de poder e conhecimento. (Bhabha, 2005, p. 61)

Lembrando, ainda, que os índios que estão fazendo sucesso na vida, fora ou nas comunidades, estão fazendo sucesso como índios. Quem deixou de ser índio e desapareceu na sociedade nacional está em algum cantinho, amargando uma tristeza profunda de não saber quem é, afinal. Se a educação corta a raiz indígena, ele perde a chance de se dar bem na vida, na própria comunidade ou em outra sociedade. Nesse sentido é que o efeito-escola pode esterilizar a potência de vida.

A linearidade fragmentada do saber dominante rompe as integrações entre os sistemas. O saber local resvala pelas rachaduras da fragmentação. É eclipsado com o mundo ao qual está ligado. Desse modo, o saber científico dominante cria uma monocultura da mente ao fazer desaparecer o espaço das alternativas locais, de forma muito semelhante à das monocul- 
turas de variedades de plantas importadas, que levam à substituição e destruição da diversidade local. (Shiva, 2003, p. 25)

As instituições salesianas da região, tanto as de ensino fundamental quanto as de ensino médio, ainda acreditam nas vantagens do 'sistema preventivo' sobre outros métodos e processos pedagógicos (Gomes, 1991, p. 147). Depois de quase um século de educação escolar preparando os alunos para serem "bons cristãos e bons cidadãos", com a utilização de métodos e processos eficientes de integração do índio à sociedade nacional, mediante uma postura de "conversão constante", é ainda constante ouvir falar em "dificuldades dos alunos em função de sua origem indígena”. Uma professora indígena declarou:

(...) os alunos indígenas sofrem vários obstáculos, discriminação, sobretudo. São discriminados pelos não indígenas porque não pertencem à mesma cultura (a branca). Eles são diferentes porque têm língua, cultura, cor diferentes da civilização branca. São lentos na aprendizagem porque acham difícil compreender tudo o que é ensinado (...). A dificuldade que percebo nos alunos indígenas é na expressão e na socialização. Eles não conseguem expressar suas idéias. Quanto às outras condiçōes, desconheço.

Essa observação de que os alunos indígenas são "tímidos" é muito comum; é uma explicação "natural", que opera como uma forma de silenciamento, como se a timidez fosse uma característica própria de crianças e jovens do interior. No entanto, se fizermos uma comparação com os alunos das escolas Pamáali (baniwa-coripaco) e Utapinopona (tuyuka), tal explicação não se sustenta. São duas escolas-piloto, duas experiências que têm sido vistas como uma possibilidade de se construir uma educação indígena aliada à luta pela afirmação das culturas e dos saberes locais, adotando um sistema de sustentabilidade escolar, educação plurilíngüe e intercultural e onde as línguas têm funções definidas e um espaço de uso e reprodução, de criação de histórias de tradução cultural como alternativas àquelas impostas pelo domínio colonial.

Os alunos destas duas escolas impressionam pela facilidade da expressão, pela alegria e pelo entusiasmo com que falam e expõem os resultados de suas pesquisas e de seus trabalhos; falam na aula o tempo todo, perguntando, contestando, ajudando os colegas; a última coisa que um visitante diria de um desses alunos é que "são tímidos". 
O eu e o Outro no ensino médio indígena: Alto Rio Negro (АМ)

Perspectivas de mudanças: caminhos em busca da emancipação?

\section{Propostas a partir das escolas indígenas Pamáali (baniwa-coripaco) e Utapinopona (tuyuka)}

Ainda que se trate de duas escolas de ensino fundamental, apresentamos a descrição destas experiências porque são escolas que nasceram da decisão de dois diferentes povos com o mesmo objetivo, porém, com encaminhamentos diferentes. O objetivo da criação destas escolas-piloto, como foram concebidas, foi oferecer às comunidades a possibilidade de seus filhos terem uma educação escolar que rompesse radicalmente com os modelos conhecidos até então, na região, orientados pelo 'sistema preventivo' de D. Bosco. É forte essa influência porque a presença salesiana é uma presença estimuladora, animadora e religiosa que, exprimindo-se em "relações interpessoais, radicadas em uma fundamental confiança nos jovens" (art. 52), produz efeitos duradouros porque trabalha com amor e dedicação; "assiste o corpo", mas "captura a alma" para libertá-la das "forças interiores", como ocorreu com o "indiozinho" da missão de Taracuá: não é fácil descrever o que se passou naquela 'alma selvagem' até chegar a uma completa transformação.

Contra esse "eficaz sistema", levantaram-se para valer dois povos os baniwa-coripaco e os tuyuka - que se propuseram, a partir de dois projetos, a inventar a própria educação escolar que, talvez, não seja um sistema tão bem estruturado, mas tem decisão e princípios bem claros. E a prática, continuamente avaliada, vai dizendo como deve ser.

Os dois projetos fazem parte de um projeto maior de educação que a FOIRN desenvolve na região, em parceria com o Instituto Socioambiental (ISA); essas organizaçôes, por sua vez, contam com recursos externos e, no caso do Projeto de Educação, contam com o apoio de Horizonte 3000/Governo Federal da Austria e Rainforest Foundation/Noruega. Contam, ainda, com o apoio da Secretaria Municipal de Educação de São Gabriel da Cachoeira, da FUNAI, administração local, do Conselho Estadual de Educação Escolar Indígena do Amazonas e da Coordenação Geral de Educação Indígena/MEC. Têm, ainda, o apoio de profissionais do Instituto de Políticas Lingüísticas (IPOL) e de outros pesquisadores.

No início do ano de 2004, foi feita uma avaliação externa e integrada dos projetos em parceria FOIRN/ISA na região do Rio Negro. Do 
Relatório, apresentado pelos cinco avaliadores, destacamos e transcrevemos três parágrafos que sintetizam os aspectos fundamentais que revelam a relevância das experiências, considerando como critério a abordagem que os projetos fazem das necessidades das pessoas que deles vão se beneficiar:

Observou-se que a Escola Tuyuka foi iniciada pela comunidade, é desenvolvida segundo seus desejos e vem se constituindo em um longo processo de discussões sobre os mais diversos assuntos. As iniciativas em seu âmbito vêm sendo desenvolvidas seguindo o seu próprio ritmo. A posse e direção da escola pelos componentes é um componente muito forte.

Quanto à Escola Pamáali, avaliou-se que esta se encontra efetivamente voltada para a formação de cidadãos Baniwa orientados para as responsabilidades de trabalho em sua comunidade, para a criatividade, o respeito aos valores próprios e para o diálogo intercultural. O Projeto Político-Pedagógico dessa escola destaca-se por marcar uma diferença com as demais escolas municipais e missionárias. A ênfase na formação de pessoas orientadas para o trabalho na comunidade é coerente com a visão de bem-estar e desenvolvimento sustentável que preconiza o movimento indígena, e tem uma expressão clara na organização da escola, na proposta curricular, no calendário, e no funcionamento da escola.

Ambas as escolas foram consideradas pelos avaliadores não apenas relevantes para as poucas comunidades que estão agora envolvidas, mas potencialmente relevantes também para todas as comunidades indígenas que desejam valorizar suas línguas e culturas. (Relatório Final - Avaliação Externa, 2004, p. 26).

\section{Propostas a partir da implantação recente do ensino médio em Pari Cachoeira, Taracuá e Assunção do Içana}

O processo de implantação de ensino médio "indígena" nas terras de Pari Cachoeira, Taracuá e Assunção do Içana foi o resultado de inúmeras reivindicações das comunidades envolvidas. $\mathrm{Na}$ ocasião, a reivindicação maior foi a da abertura imediata do ensino médio nesses três distritos, os quais estão à espera dessa iniciativa há muitos anos: Pari Cachoeira tem ensino fundamental desde 1976, com mais de 500 alunos que terminaram a $8^{a}$ série; Taracuá, com ensino fundamental completo desde 1979, com 228 alunos que concluíram até 2003; Assunção do Içana, com 102 alunos que já concluíram o Fundamental, desde 2000 até 2003; esses distritos, todos em área indígena, nunca tiveram a ofer- 
O eu e o Outro no ensino médio indígena: Alto Rio Negro (AM)

ta de ensino médio, apesar das inúmeras reivindicações à Secretaria de Estado de Educação do Amazonas.

Por isso, pode-se afirmar que o I Seminário foi decisivo, porque ali se costuraram os compromissos entre comunidades interessadas, MEC/SEMTEC e SEDUC/AM. Em poucas semanas, os distritos se organizaram, convocaram assembléias para discutir alguns pontos e tomar decisões fundamentais, de maneira que foi possível, no espaço de dois meses, dar início às ações de implantação do ensino médio nesses três distritos.

O ensino médio indígena está se propondo começar agora, nesses centros missionários de Pari Cachoeira (no Tiquié), Taracuá (no Uaupés) e Assunção (no Içana), com uma grande vitória dos professores: ${ }^{8}$ a decisão de oferecer uma educação escolar voltada para as necessidades e projetos das suas próprias comunidades e, finalmente, com os professores e lideranças desses distritos assumindo a gestão das escolas; os professores que acabam de assumir a responsabilidade do ensino médio nesses três distritos não têm experiência em educação escolar diferenciada e será preciso "inventar" essa escola, uma vez que toda a sua formação tem sido feita no sentido de preparar o índio para sair da aldeia e viver em outra sociedade.

Como consequiência, até então, o sonho de cada adolescente do ensino fundamental e do médio (onde este já existe) está sendo preparar-se para ter um emprego na sociedade dos brancos. O resultado tem sido desastroso: os jovens terminam o ensino médio, o emprego desejado não existe - pelo menos não para todos -, eles saíram das próprias comunidades para estudar, não aprenderam quase nada da sua própria cultura, não sabem trabalhar, pois passaram a viver fora do seu contexto familiar; o ensino médio também não os preparou nem para o vestibular (outra ilusão!), nem para algum tipo de trabalho profissional; não gostam mais de viver nas aldeias, alimentam sonhos de viver nas cidades, a maioria não volta para as comunidades.

\section{Enfim, uma escola diferenciada}

Por sua imensa capacidade de resistir, as nações indígenas não desapareceram ao longo dos 500 anos de colonização e de massacre cultural, mas sofreram grandes perdas; sobretudo na prática das suas reli- 
giōes, da sua cultura, algumas perderam a língua de origem; perderam muito da ciência da saúde e da alimentação sadia, tendo sido a função dos pajés uma das mais perseguidas pelos missionários, considerada, tanto por católicos como por protestantes, como rituais diabólicos.

Atualmente, há um movimento muito interessante, na região, de volta às próprias raízes, de pesquisar a própria cultura, de revitalizar as línguas maternas, de criar condições de bem-estar e prazer de viver nas próprias aldeias, enfim, de reinventar a vida, investindo em projetos de auto-sustentabilidade; as organizações indígenas vêem a educação escolar como uma ótima aliada, desde que modifiquem seus métodos e objetivos, seus programas, seus calendários, enfim, sua filosofia.

Os enormes esforços empreendidos, através dos anos, não apenas por estudiosos da academia, mas pelos próprios praticantes da cultura, de juntar ao presente essas "rotas" fragmentárias, freqüentemente ilegais, e reconstruir suas genealogias não-ditas, constituem a preparação do terreno histórico de que precisamos para conferir sentido à matriz interpretativa e às auto-imagens de nossa cultura, para tornar o invisível visível. (Hall, in: Sovik, 2003, p. 42)

Há uma vontade forte de mudar essa situação; prova isso o fato de, nos três centros missionários onde o ensino médio está começando agora, os professores e lideranças terem assumido a gestão das próprias escolas, fato inédito e corajoso, quando se sabe que foram educados para a docilidade e submissão, sempre levados a se entenderem como incapazes e tendo que receber essa educação dirigida por "pessoas de fora", porque essa era a "escola boa"; as outras eram "coisa de índio", de segunda. Tanto assim que as outras escolas, as das pequenas comunidades, eram (são ainda em muitos casos!) chamadas de "escolinhas" ou de "escolas rurais", num sentido bem pejorativo.

O desafio dos professores indígenas do Rio Negro de gerir e levar adiante o ensino médio, segundo seus objetivos atuais, traçados por eles, juntamente com as lideranças de comunidades, exige um investimento contínuo na formação dos professores. Alguns deles estão cursando o terceiro grau na Universidade Federal do Amazonas (UfAM) ou na Universidade do Estado do Amazonas (UEA), em cursos de férias, mas sem nenhum preparo para uma educação diferenciada.

Nesse sentido, o propósito de fazer o "ensino com pesquisa", de organizar os currículos por projeto, de produzir material didático nas 
O eu e o Outro no ensino médio indígena: Alto Rio Negro (AM)

línguas maternas, para dar suporte às escolas de ensino fundamental na região, precisa de assessoria especializada, com urgência.

Ao levantar essas questôes por ocasião das primeiras assembléias para definir os rumos que deverão tomar os cursos de ensino médio, os professores entenderam que, se bem trabalhadas em continuadas sessões de estudo, essas questões estariam trazendo os elementos mínimos para a elaboração do projeto político-pedagógico de cada escola. Realmente, para definir esses pontos, muitos debates terão que acontecer. Essa certeza apontou para outra necessidade: a da formação contínua desses docentes.

\section{Considerações finais}

Ao apontarmos os dispositivos pedagógicos em funcionamento no ensino médio no alto e médio Rio Negro, focalizando os efeitos que o 'sistema preventivo' da educação salesiana tem produzido ao longo desse tempo todo, desde 1920 até hoje, não ignoramos os esforços de mudança que se tem feito nos últimos anos, no sentido de "adequar os princípios cristãos à cultura indígena”. Diversas circunstâncias provocaram essa revisão por parte dos missionários: a própria Igreja Católica pós-concílio Vaticano II, por um lado, fazendo a opção preferencial pelos pobres, que teve grande repercussão em toda a América Latina, sinalizando, em relação os índios, no Brasil, a criação do Conselho Indigenista Missionário (CIMI), ligado à Confederação Nacional dos Bispos do Brasil (CNBB), que se colocou como objetivo a denúncia às agressôes sofridas pelos índios e o apoio às suas reivindicações e direitos.

De outro lado, o próprio movimento indígena, a partir de uma grande resistência, retomou a sua própria história e não permitiu o desaparecimento de suas culturas, apesar de todo o tipo de massacre, escravidão e aculturação. Este foi um dos pilares que balançou a segurança dos missionários, obrigando-os a rever suas estratégias. Quando os índios começaram a manifestar a sua desconfiança na palavra divina como fonte de verdade escrita ou falada pelos missionários, "foi preciso encontrar catequistas nativos, que traziam consigo suas próprias ambigüidades e contradições culturais e políticas, muitas vezes sob grande pressão de suas famílias e comunidades" (Bhabha, 2005, p. 62).

Cabalzar Filho (1999) cita um livro do padre salesiano Casemiro Betska (Adaptação, 1969), no qual ele mostra que foi um erro querer 
ocidentalizar tudo no trabalho com os índios e que a Igreja corria o risco de ser vítima dessa atitude; que é preciso, antes, aproveitar os simbolismos e "adaptar-se" aos costumes para que eles possam assimilar melhor a mensagem do Evangelho, "já que os índios são, no âmago de suas almas, naturalmente cristãos" (1999, p. 372). Houve, ainda, a partir de 1970, um movimento para mudar as estratégias pastorais, que passaram a utilizar-se de objetos de artesanato para enfeitar a Igreja, produtos indígenas para ofertar na missa, de modo a recuperar costumes que haviam sido fortemente condenados antes.

Segundo o autor, em 1982, o padre Afonso Casasnovas fez uma avaliação do processo de evangelização no rio Içana, em artigo publicado na revista Centenário em Foco (n. 5), onde alerta:

Não deveríamos ter medo de "perder" tempo, estudando bem a cultura e a língua deles (dos índios) para prepararmos uma corajosa revisão dos nossos métodos educativos, evangelizadores e de promoção humana. Só conhecendo o pensamento mítico dos nossos índios e descobrindo os seus valores poderemos educar e transmitir a Boa Nova de uma maneira eficiente e respeitosa. Estamos sempre estudando sua cultura, sua língua, suas lendas. Acreditamos que são eles, os baniwa, que nos vão dar o modo de viver e transmitir a Mensagem, através de uma liturgia encarnada na sua realidade. (Apud Cabalzar Filho, 1999, p. 372)

O problema é que os dois padres propõem apenas a revisão dos métodos, não se colocando jamais a possibilidade de questionar o propósito de querer fazer dos índios "bons cristãos". Tudo o que mudou atualmente foi querer que eles sejam bons cristãos "sem deixar de ser índios", ressalta Cabalzar Filho.

$\mathrm{Na}$ área da educação ocorre o mesmo: não se fez nenhuma mudança substancial nas escolas de orientação salesiana. A mudança feita no Regimento da Diocese, em 2000, é prova disso. Incluem-se algumas citações da nova legislação e dos objetivos traçados, em nível nacional, para a educação escolar indígena, fala-se em "fortalecer a língua materna de cada etnia, dar formação específica aos professores", em desenvolver "currículos e programas específicos" de acordo com as exigências da clientela a ser atendida, desenvolver a "memória histórica dos povos", suas "tradições e línguas" (...) (arts. 76-79). Mas, na prática, as escolas sequer têm um levantamento das etnias que freqüentam cada sala de aula, não se têm dados das línguas que são faladas/ 
O eu e o Outro no ensino médio indígena: Alto Rio Negro (AM)

escritas pelos alunos e pelas comunidades a que pertencem; e os currículos e programas são exatamente os mesmos formulados pelo Estado para todos os estudantes do Amazonas.

(...) os sistemas locais de saber no mundo inteiro (...) têm sido subjugados por políticas de eliminação, não por políticas de debate e diálogo (...). Primeiro fazem o saber local desaparecer, simplesmente não o vendo, negando sua existência (...). Quando o saber local aparece de fato no campo da visão globalizadora, fazem com que desapareça negando-lhe o status de um saber sistemático (...). (Shiva, 2003, p. 21-23)

O Estado ignora as especificidades, seja em relação à formação dos professores, seja no incentivo à elaboração e publicação de materiais adequados ou à flexibilização de calendários e de formas de avaliação e registros. No nosso entendimento, primeiro se faz uma proposta, se experimenta, se avalia e, somente então, se "regimenta", se for o caso, para garanti-la. No caso do Rio Negro, se "regimentou" antes de se ter uma proposta. Ou melhor, neste caso, a proposta é a que está clara no Regimento: o "sistema preventivo" está garantido no Regimento da Diocese, como conceito e formas de operacionalização.

Como, para Hall (in: Sovik, 2003, p. 44), a questão não é o que as tradições fazem de nós, mas o que nós fazemos das nossas tradiçôes, resta-nos observar se os índios vão continuar "regimentados" no modo de ser do 'sistema preventivo' ou vão construir o ensino médio indígena no alto e médio Rio Negro a partir de um processo "de se tornar", "de se fazer" a partir de suas tradiçõos!

Recebido em maio de 2006 e aprovado em junho de 2006.

\section{Notas}

1. Pesquisa realizada por Judite Gonçalves de Albuquerque, em março de 2004.

2. Se considerarmos as etnias e o número de alunos que delas fazem parte, com certeza, a afirmação é verdadeira, mas se considerarmos os objetivos, as metas, os métodos, enfim, os currículos que orientam as ações dessas escolas, é possível chegar a outras conclusōes.

3. Ver Regimento Escolar da Diocese de São Gabriel (2000), art. 3º.

4. Os estabelecimentos de ensino pertencentes à Diocese de São Gabriel da Cachoeira, em cuja administração estão as Filhas de Maria Auxiliadora, são hoje em número de onze, nos municípios de Barcelos, Santa Isabel e São Gabriel da Cachoeira. 
5. Poder pastoral é uma denominação dada ao poder da Igreja por Foucault.

6. “Abecedário Gilles Deleuze: testemunho”, entrevista a Claire Parnet, gravada em vídeo, entre 1988-1989, e só publicada após a sua morte. [Versão francesa disponível em: http:/ cura.free.fr/28deleuze.html].

7. A partir daqui, todas as referências a esse Seminário serão indicadas, simplesmente, pela expressão I Seminário e as citaçōes serão tiradas do Relatório feito pela equipe do Conselho de Professores Indígenas do Alto Rio Negro (COPIARN).

8. Insistimos que o “Ensino Médio Indígena” está começando agora, no Rio Negro, porque em Iauaretê - única escola em área indígena que oferece ensino médio - e nas escolas de ensino médio em São Gabriel da Cachoeira - fora de área indígena -, ainda que $90 \%$ dos alunos sejam indígenas e as escolas estejam cadastradas como "indígenas" (desde 1997), não o são, como estamos tentando demonstrar.

\section{Referências bibliográficas}

BHABHA, H. O local da cultura. Belo Horizonte: UfmG, 2005.

BRASIL. Ministério de Educação. Secretaria de Educação Fundamental. Programa Parâmetros em Ação Educação Escolar Indígena: as leis e a educação escolar indígena. Brasília, DF: MEC/SEF, 2001.

BRASIL. Ministério de Educação. Secretaria de Educação Média e Tecnológica. Políticas de Ensino Médio para os povos indígenas; anais do Seminário. Brasília, DF: SEMTEC/Programa Diversidade na Universidade, 2003.

BRASIL. Ministério de Educação. Secretaria de Educação Média e Tecnológica. Diversidade na educação, reflexōes e experiências. Brasília, DF: SEMTEC/ Programa Diversidade na Universidade, 2003.

CABALZAR FILHO, A. O templo profanado: missionários salesianos e a transformação da maloca tuyuka. In: WRight, R.M. (Org.). Transformando os deuses: os múltiplos sentidos da conversão entre os povos indígenas no Brasil. Campinas: UNICAMP, 1999.

FOIRN/ISA. Mapa-livro: povos indígenas do alto e médio Rio Negro. 2. ed. Brasília, DF: MEC/SEF, 2000.

FOIRN/ISA. Macrozoneamento participativo das terras indigenas do alto e médio Rio Negro; mapa com textos explicativos. São Gabriel da Cachoeira: FOIRN; São Paulo: ISA, 2003. 
O eu e o Outro no ensino médio indígena: Alto Rio Negro (AM)

FOIRN/ISA. Avaliação externa de projetos em parcerias na Região do Rio Negro Brasil: relatório final. São Gabriel da Cachoeira: FOIRN/ISA, 2004.

GIACONNE, A. Os Tucanos e outras tribos do rio Uaupés; Afluentes do Rio Negro; Amazonas: notas etnográficas de um missionário salesiano. São Paulo: Imprensa Oficial do Estado; Associação Brasileira dos Amerindianistas, 1949.

GOMES, D.M. Homem: objetivação de uma sujeição. 1991. Dissertação (Mestrado) - Pontifícia Universidade Católica de São Paulo, São Paulo.

GORE, J.M. Foucault e educação: fascinantes desafios. In: SiLVA, T.T. (Org.). O sujeito da educação: olhares foucaultianos. Petrópolis: Vozes, 1994.

HALL, S. Da diáspora: identidades e mediaçôes culturais; organização L. Sovik. Belo Horizonte: UfMG; Brasília, DF: UNESCO no Brasil, 2003.

INSTITUTO SOCIOAMBIENTAL (ISA). Povos indígenas no Brasil 1991/1995. São Paulo: ISA, 1996.

INSTITUTO SOCIOAMBIENTAL (ISA). Povos indígenas no Brasil 1996/2000. In: Ricardo, C.A. (Ed.). Porto inseguro: o que os brasileiros pensam dos índios? São Paulo: ISA, 2000.

MACARÃ, M. et al. Saiña hoa bauaneriputi keomasire iñabese yugeña saiña nemoripu. São Paulo: FOIRN/ISA, 2004.

NOVAES, S. C. Jogo dos espelhos: imagens da representação de si através dos outros. São Paulo: EDUSP, 1993.

NOVAES, S. C. A épica salvacionista e as artimanhas da resistência: as missões Salesianas e os Bororo de Mato Grosso. In: Wright, R.M. (Org.). Transformando os deuses: os múltiplos sentidos da conversão entre os povos indígenas no Brasil. Campinas: UNICAMP, 1999.

OLIVERIA, G.M. O que quer a lingüística e o que se quer da lingüística na pedagogia da diferença?: a delicada questão da assessoria ao movimento indígena. In: SECCHI, D. (Org.). Ameríndia: tecendo os caminhos da educação escolar. Cuiabá: SEE/CEI, 1998.

PADRÃO, L.N (Coord.). Avaliação externa e integrada, projetos em parcerias FOIRN/ISA na região do Rio Negro Brasil: relatório final. 2004. 
SÃO GABRIEL DA CACHOEIRA (AM). Secretaria Municipal de Educação. Programa Construindo uma educação escolar indigena: formação de professores indígenas; habilitação para o magistério indígena; 1977-2000.

SHIVA, V. Monoculturas da mente: perspectivas da biodiversidade e da biotecnologia. São Paulo: Gaia, 2003.

SILVA, A.B.A. A civilização indígena do Uaupés: observações antropológicas etnográficas e sociológicas. 2. ed. Roma: Ateneo Salesiano, 1975.

SOUZA-SANTOS, B. Para um novo senso comum: a ciência, o direito e a política na transição paradigmática. 2. ed. São Paulo: Cortez, 2000. v.1.

TENÓRIO, H.P. et al. Kiti wederira tuohoarira (histórias contadas, ouvidas e escritas). São Gabriel da Cachoeira, AM: FOIRN; São Paulo: ISA, 2002. 